botany, the practice of medicine, chemistry, Privy Council at the suggestion of the anatomical demonstrations, materia medica, and midwifery, -he is required to listen while certain men read discourses on these subjects during four hours every morning, Sundays excepted; and again, in the afternoon, he is called upon to attend lectures upon anatomy, physiology, and morbid anatomy, from three till four, and to listen again in the evening to discourses upon the principles and practice of surgery, and forensic medicine, from eight $o^{\prime}$ clock till nine. But there is an " interval" for " hospital practice and practical anatomy" from twelve to three, or rather from twelve to half-past two in the months of November, December, and January. In this "interval" the student must consume at least three quarters of an hour in walking to and from the nearest hospital ; he must consume another portion of time at dinner, he ought to devote at least two hours to the practice of the hospital, and if he were to devote the whole of the "interval," that is, three hours to dissecting, he would be much better employed than in attending lectures upon botany and some other subjects which appear in the catalogue.

This table proves that it is absolutely impossible for students to comply with the terms of the "regulations," yet they are enforced with the most scrupulous, not to say infamous, exactness. Hence, conviction is carried home to every mind that the object of the medical corporations is to secure to themselves, their relatives and dependents, the receipt of innumerable fees, and that the careful, judicious, honourable, and economical education of the medical student, forms no part, no, not even the smallest item, of the "system" which they advocate.

\title{
THE CHOLERA.
}

Ix another part of this day's LANCET will be found some extracts from the notification respecting the Cholera, published by the Board of Health. We have not reprinted the document in full, for the original is cha. racterised by a pompousness and verbosity of style which would have excited the envy of Mrs. Radicliffe. It contains also a caution against smuggling, which we have left out, but every-thing else of importance is preserved. In soliciting the attention of our readers to this remarkable document in the sanatory history of Great Britain, we must entreat them for a moment to dismiss from their minds the question re. garding the mode in which the disease is propagated. Whatever be the nature of this fact, there are certain duties which the trustees of the public health should invariably discharge, in anticipation of the outbreaking of a disease so rapidly fatal in its progress as that which now excites the pub. lic apprehension.

It is perfectly obvious that a wise provision against the occurrence of such a calamity should provide against all the objects by which epidemic diseases of every description are notoriously engendered and sus. tained. Before the irruption of the disorder, all the external agents capable of infuencing public health should be put into the least offensive state; ventilation, draining, the abatement of nuisances, the shunning of encumbered populations, the examination of the food and drink of the commu. nity, should all receive the most assiduous attention. Thus far, we presume, no controversy can exist even between those who hold the most opposite sentiments on other branches of this subject.

Again, it is equally beyond dispute that measures should be prepared for the effectual administration of relief to those who may be attacked by the disease. In short, an efficient and well-organised system of medical police should be prepared for instant adoption.

The last general rule we may lay down as a law never to be swerved from, and 
one equally removed from difierences of commendations, not to speak of their imopinion, is, that the seclusion of the sick practicability, is sufficiently obvious; but should be insisted on, and every means the last and most fearful blunder remains to derised for mitigating the annoyances of be stated. those whose liberties are sacrificed to the public weal. To put a case in point, suppose it be necessary to exclude a labouring man whose family depends on his free egress for their subsistence. It is obvious that the community has no right to deprive that individual of his liberty, without making fill and adequate provision to prevent the privations that his family may sustain.

Having premised these general data we are the better prepared to estimate the degree of utility of the manifesto just published by the Board of Health. What then are its anticipatory measures? Magistrates, clergymen, and persons of authority, are invited to pay some attention to the state of rentilation, "the formation of district com. mittees is suggested, of two or three persons, one to be a member of the medical profession, to watcl over the state of health of the district; and houses are advised to be kept in riew for the reception of patients." Such is the essence of all the anticipatory measures, for the advising of which Sir Henry Ifalford and his colleagues receive each some hundreds per annum. We might smile at their imbecility, did we not know the mischievous neglect of all efficient sanatory measures which the official nature of these suggestions will tend to occasion. Feeling this conviction, however, we cannot conceal our indignation at the crude, imperfect, and reckless manner, in which the notifica. tion is put forward.

Again, if we turn to some other points in this document, what melancholy examples of thoughtlessness do we find! Among the articles recommended to be destroyed after a case bas occurred are " papers!" clothes are to be boiled in a strong ley! nurses, and we presume physicians, are to be placed in quarantine! \&c. The absurdity of these re-

In the event of the disease assuming the terrific shape it has worn in some parts of the continent, STRONG BODIES OF TROOPS are to be drawn round the in. fected district, and all intercourse with the surrounding country cut off !

Now, let every man, no matter what his opinions on the transmissibility of the dis. ease, just mark this proposition with due attention. If the disease be contagious, the healthy inhabitants of the devoted district are cooped up in actual contact with the malady! If it be local, aerial, or terrestrial, they are chained down within the very arena of the exciting cause! We may inform the Board, for they evidently know not the facts, of the adoption and result of a similar horrible experiment enforced in the town of Omoplaw in Poland. The majority of the inhabitants were annihilated, and the survivors only escaped by the restriction being removed. When the senseless officials resolved upon seclusion, they ought to have lnown the difference between cutting off intercourse between towns, and the dispersion of a too crowded population over an uninhabited district. Such is the plan which should be pursued, wherever the dis. ease rages with unusual fury. The condensed population should be dispersed, and distributed under surveillance in the adjacent country.

The Board of Health, then, having proved itself to be only an incubus on the measures which, but for their existence, would be adopted by the community themselves, we call on the parishes to take the matter into their own hands. Let Committees be formed, comprising all the intelligent and ofitcial inhabitants, with a medical section composed of all the legally-qualified practitioners in the district, and let minute preparations be forthwith made for the re= 
ception of an enemy which we may find it impossible to keep at a distance.

Non-medical Coroners are certainly the oddest mortals in existence, and are always amusing, if never instructive. Their peculiarities are without number. We thought long ago that we had run through the whole list of their drolleries, but now find that we are very agreeably mistaken. The medical public will be somewhat amused in perusing the following communicátion :-

\section{"To the Editor of The Lancet.}

"SrR,-An inquest was held at this place a short time since, and the verdict, totally against the real evidence, and exhibiting most marked ignorance of the laws of the animal economy, evidenced most strongly that which you have so strenuously advocated-the impropriety of an attorney acting as coroner, instead of a practitioner in medicine. The deceased, in a fit of feverish delirium, went to the sea, and on being afterwards seen flouting, was taken up, nearly lifeless. Measures for resuscitation succeeded. He conversed, drank tea, had alvine and urinary evacuations, remarked on his state, and tuen three hours and a half from his being taken from the water, died. You will ask, " From what?" So ask I.

"I had the satisfaction of leaving him in the care of his usual attendant, recovered from the submersion, and merely wanting the ordinary means of arresting the very great reaction that would ensue; but stimulus was continued, though he was in a marked perspiration, and the abstraction of blood was not had recourse to.

"I was surprised to hear of his death, and more surprised to hear that the jury returned a verdict, founded on the medical evidence, that "he died from suffocation, from water hating got into the trachea or uind-pipe, from having laid so long in such a position." Now this suffocation from water in the trachea, took place after conversation, drinking, \&c., three hours and a half after having been taken out of the sea. What lind of a trachea could he have, for salt water to remain so long in it, and not produce irritation?

"I shall be glad to know what steps I can take to disturb such a verdict, which I objected to at the time.

"I am, Sir, your obedient servant, IV. HuLKe, jun., Surg.

Deal, Oct. 25th, 1831.
We are unable to afford our corr espond. ent any assistance in such a case, as the sea would care very little about an indict. ment for manslaughter. If there be ground for charging any person with having been instrumental in causing the death of the party in question, then we may show Mr. HuLKE how he may reach the ends of justice without disturbing the verdict. We cannot, however, dismiss the subject on this occasion, without requesting Mr. HULKE to furnish us with a detailed account of the proceedings of the Inquest ; and more especially anxious are we for that part of the evidence which induced the jury to return such an extraordinary verdict.

\section{$=$ \\ EXTRACTS FROM TIIE}

\section{PUBLIC NOTIFICATION RESPECTING THE CHOLERA MORBUS,} ISSUED BY THE PRIVY COUNCIL AT THE
INSTANCE OF THE

\section{BOARD OF HEALTH.}

\section{Whitehall, Oct. 20, 1831.}

Ir is recommended that in every town and village, commencing with those on the coast, there should be established a Local Board of Health, to consist of the chief and other magistrates, the clergyman of the pa. rish, two or more physicians or medical practitioners, and three or more of the principal inhabitants; and one of the medical members should be appointed to correspond with the Board of Health in London.

Every large town sliould be divided into districts, having a district committee of two or three members, one of whom should be of the medical profession, to watch over its health, and to give the earliest information to the Board of Fealth in the town, whose instructions they will carry into effect.

It is of the utmost importance that the very first cases of cholera which may apyear should be made known as early as possible. Success in the treatment of the cholera mainly depends on medical assistance having been given in the earliest stage of the disease.

To separate the sick from the healthy, one or more louses should be kept in eacl town or its neighbourhood, to which every case of the disease, as soon as detected, might be removed, provided the family of 